beweis geführt werden könnte, und welches dem quamquam an dentlichkeit und daher auch an möglichkeit - undeutliche, schwer verständliche oder unverständliche formen bildet die sprache nicht oder stösst sie aus und ersetzt sie durch andere - gewiss vorzuziehen ist.

Hamburg.

Heinrich Köstlin.

\title{
6. Liv. XXVI, 34 .
}

In dem strafurtheil über die Campaner lässt sich eine dreifache abstufung wahrnehmen: 1) das urtheil über den adel $(2-5)$ 2) das mit Campanos omnes beginnende über die grosse masse des volks $(6-10)$ und 3$)$ das über den senat und die behörden (11). Die letzte classe verliert das vermögen und die freiheit; das volk bleibt frei, verliert aber das römische und latinische bürgerrecht und muss auswandern. Hinsichtlich des a d els werden verschiedene bestimmungen getroffen, weil über ihn nicht summarisch, sondern familienweise verhandelt wurde. Das letztere war wahrscheinlich veranlasst durch die vielen verwandtschaftlichen beziehungen zwischen den römischen richtern und den campanischen delinquenten. Denn nur auf diese weise konnten die einzelnen senatoren hoffen, ilıre pflicht gegen den staat, die strengste bestrafung verlangte, mit der von dem natürlichen gefühl gebotenen schonung der eigenen verwandten in einklang setzen zu können. Livius unterscheidet bei der bestrafung drei klassen: 1) die hauptschuldigen verlieren ilır vermögen und werden mit weib und kind in die sklaverei verkauft; eine billige ausnahme wird nur zu gunsten derjenigen töchter gemacht, die schon vor der übergabe der stadt in andere orte weggeheirathet hatten; 2) eine zweite classe - offenbar diejenigen, welche zwar stark gravirt waren, aber nicht genügend überfülırt werden konnten und zudem im senate kräftige fürsprecher fanden - wird für spätere aburtheilung im gefangniss aufbewahrt, und damit war ihnen zugleich die hoffnung gegeben, später, wenn sich die gemüther etwas beruhigt batten, glimpflicher wegzukommen; 3) eine dritte klasse bekam einen theil ihrer güter und also offenbar auch die freiheit wieder zurück. Die worte indessen, in denen dies letztere urtheil enthalten ist, harren noch einer befriedigenden erklärung. Sie lauten: aliorum campanorum summam etiam census distinxerunt, publicanda necne bona essent. pecua captiva praeter equos, et mancipia praeter puberes virilis sexus, et omnia, quae solo non continerentur, restituenda censuerunt dominis. Weissenborn vermuthet, dass etiam auf in familias zu beziehen sei, so dass, wie bei einigen „die verwandtschaftsverhältnisse der massstab, der leitende grundsatz" gewesen seien, so bei den übrigen (aliorum) das vermögen. Es genügt ihm 
diese erklärung freilich selbst nicht, und er bescheidet sich zu sagen, dass sinn und construction der worte dunkel seien. Indessen sagt Livius keineswegs, dass „die verwandtschaftsverhältnisse der massstab, der leitende grundsatz" gewesen seien, sondern lediglich, dass die aburtheilung familienweise erfolgte; dass dann bei der entscheidung über schuld oder unschuld der einzelnen die verwandtschaft mitgespielt hat, ist zwar glaublich und natürlich, aber für die formelle behandlung der sache von keinem belang. Und ferner was wäre das für ein entsetzlicher gedanke, dass die grösse des vermögens über schuld oder unschuld der einzelnen lätte entscheiden sollen - denn darauf würde Weissenborns erklärung, wenn wir ihn recht verstanden haben, hinauslaufen. Darin aber hat er recht, dass das subject von distinxerunt kein anderes sein kann, als das von censuerunt, nämlich die recht sprechenden senatoren. Halten wir dies fest, so ist der gedanke der schwierigen stelle dieser: Im vorhergehenden war von zwei classen von angeklagten die rede: bei den einen wurde das urtheil noch suspendirt, die andern wurden mit ihren familien zum verlust des vermögens und der freiheit verurtheilt. Jedoch machte das rechtsgefühl des senates unter den kindern eine distinctio und zwar zu gunsten der nach auswärts verheiratheten töchter. Eine solche distinctio wurde auch bei der dritten classe der angeklagten gemacht, als es sich um die frage handelte, ob ihnen, ausser der freiheit, auch das vermögen in seinem ganzen umfang (summam etiam census) zurückgegeben werden solle oder nicht; und es wurde beschlossen, dass ihnen ihre güter zurückerstattet werden sollten, jedoch erst nach ausscheidung derjenigen bestandtheile, durch deren zurückgabe für Rom möglicher weise eine neue gefahr hätte entstehen und wiederholte aufstandsversuche hätten begünstigt werden können; es waren dies 1) pferde, 2) erwachsene männliche sklaven und 3) grund und boden. Wir haben also den punkt vor pecua in ein kolon zu verwandeln, da das mit pecua eingeführte im engsten zusammenhang mit dem vorhergehenden steht. Damit dürfte auch Weissenborns bemerkung, dass die verbindung unklar sei, erledigt sein.

Augsburg.

Fr. Mezger.

\section{B. Zur paläographie.}

6. Paläographisches und unpaläographisches.

Welche mühe in philologischen seminarien aufgewendet wird, um die junge generation zu einer gerechten würdigung der handschriftlichen überlieferung anzuhalten, ist zur genüge bekannt; und doch ist die für die vertheidigung aufgebotene kraft so oft verschwendet, wenn man aus erfahrung: weiss, wie viel weniger ge- 